Article

\title{
Study of In Vitro and In Vivo Carbamazepine Release from Coarse and Nanometric Pharmaceutical Emulsions Obtained via Ultra-High-Pressure Homogenization
}

\author{
Juan D. Echeverri ${ }^{1}$, Maria J. Alhajj ${ }^{2}{ }^{\oplus}$, Nicolle Montero ${ }^{2}{ }^{\oplus}$, Cristhian J. Yarce ${ }^{2}{ }^{(D}$, \\ Alvaro Barrera-Ocampo ${ }^{3}$ (D) and Constain H. Salamanca ${ }^{1,2, *}$ (i) \\ 1 Programa de Maestría en Formulación de Productos Químicos y Derivados, Facultad de Ciencias Naturales, \\ Universidad Icesi, Calle 18 No. 122-135, Cali 76003, Colombia; juandiegoqf@hotmail.com \\ 2 Laboratorio de Diseño y Formulación de Productos Químicos y Derivados, Facultad de Ciencias Naturales. \\ Universidad Icesi, Calle 18 No. 122-135, Cali 76003, Colombia; mariajoalhajj@hotmail.com (M.J.A.); \\ nicollemontero76@gmail.com (N.M.); cjyarce@icesi.edu.co (C.J.Y.) \\ 3 Departamento de Ciencias Farmacéuticas, Facultad de Ciencias Naturales, Universidad Icesi, \\ Calle 18 No. 122-135, Cali 76003, Colombia; aabarrera@icesi.edu.co \\ * Correspondence: chsm70@gmail.com
}

Received: 17 February 2020; Accepted: 23 March 2020; Published: 26 March 2020

check for updates

\begin{abstract}
In the past decade, pharmaceutical nanotechnology has proven to be a promising alternative for improving the physicochemical and biopharmaceutical features for conventional pharmaceutical drug formulations. The goal of this study was to develop, characterize, and evaluate the in vitro and in vivo release of the model drug carbamazepine (CBZ) from two emulsified formulations with different droplet sizes (coarse and nanometric). Briefly, oil-in-water emulsions were developed using (i) Sacha inchi oil, ultrapure water, Tween ${ }^{\mathrm{TM}} 80$, and $\mathrm{Span}^{\mathrm{TM}} 80$ as surfactants, (ii) methyl-paraben and propyl-paraben as preservatives, and (iii) $\mathrm{CBZ}$ as a nonpolar model drug. The coarse and nanometric emulsions were prepared by rotor-stator dispersion and ultra-high-pressure homogenization (UHPH), respectively. The in vitro drug release studies were conducted by dialysis, whereas the in vivo drug release was evaluated in New Zealand breed rabbits. The results showed that nanoemulsions were physically more stable than coarse emulsions, and that CBZ had a very low release for in vitro determination $(<2 \%)$, and a release of $20 \%$ in the in vivo study. However, it was found that nanoemulsions could significantly increase drug absorption time from $12 \mathrm{~h}$ to $45 \mathrm{~min}$.
\end{abstract}

Keywords: carbamazepine; coarse emulsion; in vitro/in vivo drug release; nanoemulsion; ultra-high-pressure homogenization

\section{Introduction}

In the biopharmaceutical classification system (BCS), four categories have been defined for pharmacological active ingredients in relation to their respective physicochemical features, such as solubility and permeability [1-4]. In accordance with the aforementioned BCS, drugs that are part of category II (high permeability and low solubility in aqueous media) $[5,6]$ have been a subject of great interest for the pharmaceutical sector, which continuously seeks to improve these characteristics through the development of new or improved pharmaceutical dosage forms. Thus, pharmaceutical nanotechnology has proven to be an interesting alternative to enhance the physicochemical and biopharmaceutical properties of such compounds, where the most studied and reported systems involve liposomes [7-13] and polymeric nanoparticles [14-18]. However, to date, the available 
information about other types of formulations, such as nanoemulsions, is much more limited [19-25]. This lack of knowledge may be because such heterodispersed systems are widely known to have thermodynamic problems. Therefore, the development of these heterodispersed formulations is quite complex and usually requires the use of more ingredients and the employment of more unit operations during the manufacturing process. However, these heterodispersed systems have also shown great pharmaceutical benefits, such as enhanced organoleptic characteristics [26,27] and improved physicochemical stability [28,29], and the ability to modify several biopharmaceutical features for a wide range of nonpolar drugs [30,31].

Currently, one of the most promising strategies used for the development of emulsified systems on a nanometric scale is ultra-high-pressure homogenization (UHPH) [32]. This technique is based on a high-energy dispersion process, where a conventional emulsion (coarse emulsion) is passed through a micrometric diameter nozzle, causing high turbulence, shear, and cavitation [33]. Consequently, UHPH allows emulsified systems to reach droplet sizes between 10 and $500 \mathrm{~nm}$ with very low polydispersity, which has a favorable impact on the physical stability of these formulations [34-37].

Conversely, it is important to note that the information available about the in vitro and in vivo release of CBZ from emulsified oral formulations with different droplet sizes is very limited. Therefore, the main goals of this study were focused on two aspects: (i) the development and characterization of different emulsified CBZ formulations with different droplet sizes (coarse and nanometric), and (ii) evaluation of the in vitro and in vivo drug release from both emulsified formulations.

\section{Materials and Methods}

\subsection{Materials}

CBZ and sacha inchi oil (SIO) were provided by Tecnoquimicas S.A Pharmaceutical Company (Cali, Valle del Cauca, Colombia) and Nutresacha SA (Santander de Quilichao, Cauca, Colombia), respectively. Sorbitan oleate (Span ${ }^{\mathrm{TM}} 80$, hydrophilic-lipophilic balance $(\mathrm{HLB})=4.3$ ) and Polysorbate 80 (Tween $^{\text {TM }}$ 80, HLB = 15) were purchased from Croda (Snaith, UK). Methyl-paraben and propyl-paraben were acquired from Sigma-Aldrich (St. Louis, MO, USA). Water Type II (ultrapure water) was obtained via a Millipore Elix Essential purification system (Merck KGaA, Darmstadt, Germany), while the water employed for high-performance liquid chromatography (HPLC) was purified using a Sartorius Arium-Pro (Sartorius AG, Gotinga, Germany). All solvents were of analytical reagent grade.

\subsection{SIO/Water Interface Physicochemical Characterization}

\subsubsection{SIO/Water Partition Assay}

The partition study of CBZ between SIO and ultrapure water was conducted in an incubated orbital shaker (Inkubator 1000 with Unimax 1010, Heidolph Instruments, Schwalbach, Germany). For this, $2.4 \mathrm{~g} \mathrm{CBZ}$ was added to $50 \mathrm{~mL}$ of the oil phase (Mixture 1) with a stirring speed of $400 \mathrm{rpm}$ for $45 \mathrm{~min}$ at $37{ }^{\circ} \mathrm{C}$. Subsequently, $50 \mathrm{~mL}$ of ultrapure water was added to Mixture 1, forming a ternary mixture (CBZ, SIO and ultrapure water) which was stirred at $400 \mathrm{rpm}$ for $45 \mathrm{~min}$ at $37^{\circ} \mathrm{C}$. Once the CBZ was distributed in the respective phases, it was left to rest for 3 min, during which a complete separation of SIO and ultrapure water occurred. Immediately after separation, $1 \mathrm{~mL}$ aliquots were taken from the oil and water phases (initial time), and the concentrations were determined using a UV/Vis spectrophotometer (UV-1800, Shimadzu, Milton Keynes, UK). Calibration curves of CBZ in SIO and ultrapure water were determined using serial concentrations of 1.0, 3.0, 5.0, 10.0, 15.0, 20.0, and $23.75 \mathrm{mg} / \mathrm{mL}$. Finally, the ternary mixture was left to rest for $8 \mathrm{~h}$ (final time), after which $1 \mathrm{~mL}$ aliquots were taken from each respective phase and the concentration was measured by UV/Vis spectrophotometry. 


\subsection{2. $\mathrm{SIO} /$ Water Interface Effect}

The value of the interfacial tension generated between SIO and ultrapure water $\left(\gamma_{\mathrm{o} / \mathrm{w}}\right)$ was determined using the pendant drop method with a tensiometer (OCA15EC, Dataphysics Instruments, Filderstadt, Germany). Briefly, a drop of the oil was deposited into $3 \mathrm{~mL}$ of ultrapure water, where the oil was automatically dispensed from a $500 \mu \mathrm{L}$ syringe (DS 500GT, Dataphysics Instruments, Filderstadt, Germany) equipped with a needle dispenser (SNC 021/011, Dataphysics Instruments, Filderstadt, Germany), while the water was contained in a flat-faced quartz cell. The instrument recorded video captures with an IDS USB 3 camera (IDS Imaging Development Systems GmbH, Obersulm, Germany) using appropriate software (SCA 21, Dataphysics Instruments, Filderstadt, Germany). Finally, the same procedure was repeated with the incorporation of CBZ into SIO at concentrations of 1.0, 4.0, 8.0, 12.0 , and $23.8 \mathrm{mg} / \mathrm{mL}$. Each measurement was conducted in triplicate using freshly prepared samples.

\subsection{Elaboration of Emulsified Formulations}

The schematics of the elaboration process, physicochemical characterization of the emulsified systems, and drug release assays are depicted in Figure 1.

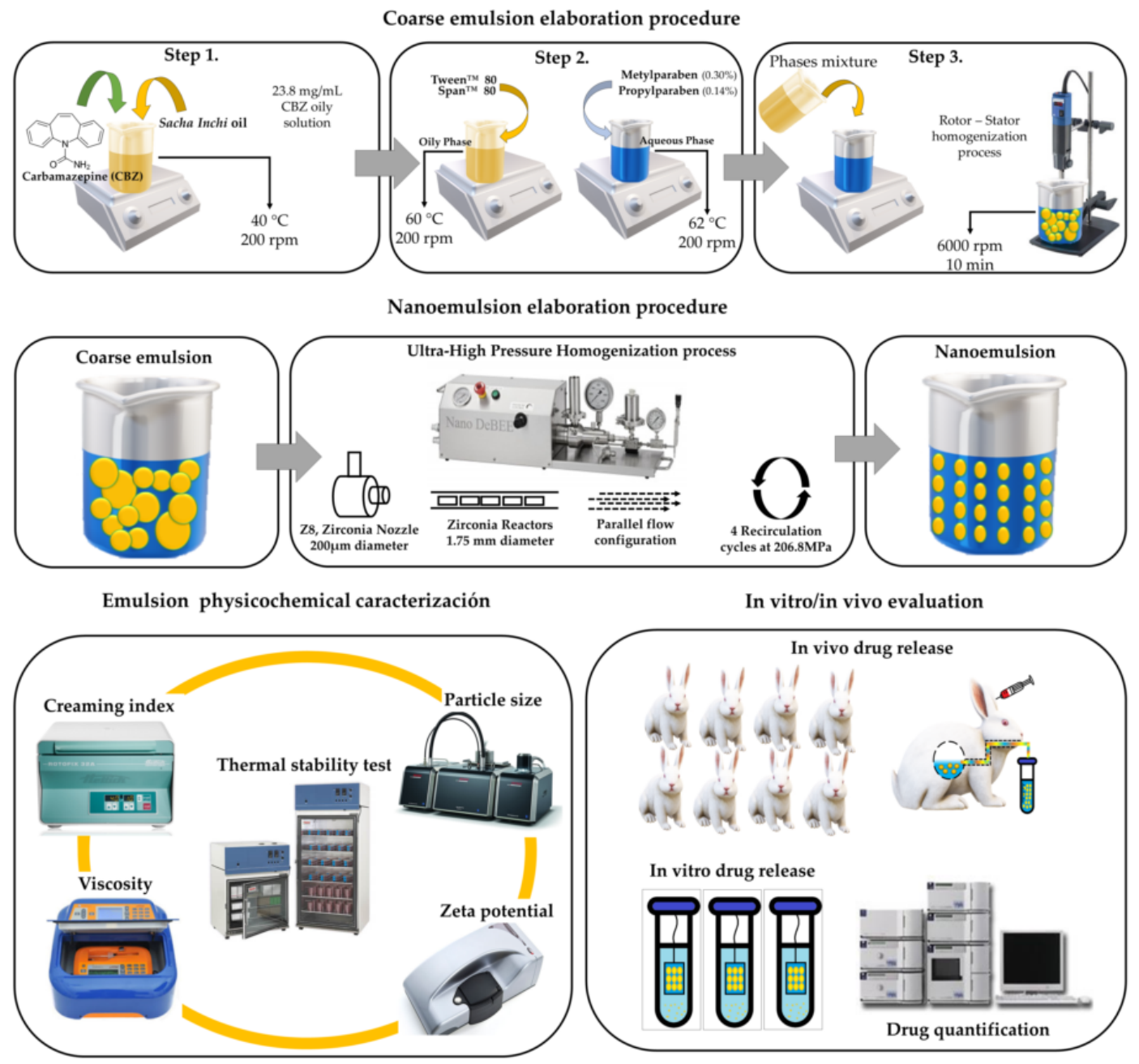

Figure 1. Schematic of the elaboration process, physicochemical characterization, and drug release assays for emulsified carbamazepine (CBZ) formulations.

\subsubsection{Coarse Emulsions}

CBZ was added into SIO at $40{ }^{\circ} \mathrm{C}$ under constant stirring (200 rpm) until an oily solution of $23.8 \mathrm{mg} / \mathrm{mL}$ was attained. The oily solution and ultrapure water were then heated to $60^{\circ} \mathrm{C}$ and $62{ }^{\circ} \mathrm{C}$, 
respectively, at which point where methyl-paraben and propyl-paraben preservatives were added into the ultrapure water to concentrations of $0.3 \% w / w$ and $0.14 \% w / w$. In contrast, Tween ${ }^{\mathrm{TM}} 80$ and $\operatorname{Span}^{\mathrm{TM}} 80$ surfactants were added into the oily solution at $2 \% w / w$, providing an HLB value of the surfactant blend of 8 , which is, in fact, the required HLB of the oil that leads to high stabilization of such emulsified systems $[37,38]$. Afterward, the oily phase was poured into the aqueous phase, using an Ultraturrax IKA ${ }^{\circledR}$ at $6000 \mathrm{rpm}$ for $10 \mathrm{~min}$, and the emulsified systems were cooled to room temperature $\left(25^{\circ} \mathrm{C}\right)$ to obtain the coarse emulsions.

\subsubsection{Nanoemulsions}

Once the coarse emulsions were prepared, $600 \mathrm{~g}$ measures were subjected to UHPH using a Nano DeBEE Laboratory Homogenizer (BEE international, South Easton, MA, USA), where the operating conditions employed were: zirconia nozzle (Z8) with an orifice diameter of $200 \mu \mathrm{m}$, six zirconia reactors with orifice diameter of $1.75 \mathrm{~mm}$, a pressure of $3 \times 10^{4} \mathrm{psi}(206.8 \mathrm{MPa})$, and a parallel flow configuration, with a total of four recirculation cycles. These conditions were previously defined by means of a series of tests conducted before the development of the nanoemulsions.

\subsection{Thermal Stability Assay of Emulsions and Nanoemulsions}

The coarse emulsions and nanoemulsions were placed in Falcon ${ }^{\mathrm{TM}} 15 \mathrm{~mL}$ conical centrifuge tubes, which were subsequently left at two temperature conditions $\left(60^{\circ} \mathrm{C} \pm 2{ }^{\circ} \mathrm{C}\right.$ and $\left.4.0^{\circ} \mathrm{C} \pm 0.5^{\circ} \mathrm{C}\right)$. For this, each thermal condition was varied every $48 \mathrm{~h}$ for 2 weeks, starting at $60^{\circ} \mathrm{C}$ for the first $48 \mathrm{~h}$, then at $4{ }^{\circ} \mathrm{C}$, etc. The stability parameters evaluated were creaming index, droplet size, viscosity, zeta potential, electrical conductivity, and $\mathrm{pH}$.

\subsubsection{Creaming Index}

In this case, the freshly made coarse emulsion and nanoemulsion were added to Falcon ${ }^{\mathrm{TM}} 15 \mathrm{~mL}$ conical centrifuge tubes (diameter $=1.5 \mathrm{~cm})$ and centrifuged at $3000 \mathrm{rpm}(150 \mathrm{RFC})$ for $4 \mathrm{~h}$ in a centrifuge (Rotofix 32A, Hetttich GmBH, Tuttlingen, Germany). The value of the creaming index (CI) was determined as

$$
C I=\frac{H_{S}}{H_{E}} \times 100
$$

where $\mathrm{H}_{\mathrm{S}}$ is the sediment height and $\mathrm{H}_{\mathrm{E}}$ is the sample height before centrifugation.

\subsubsection{Droplet Size}

For the coarse emulsion, the droplet size distribution was assessed using a laser particle sizer Analysette 22 MicroTec Plus (Fritsch, Idar-Oberstein, Germany) with an automatic analysis setup. First, $\sim 0.5 \mathrm{~g}$ of the emulsion was diluted with $10 \mathrm{~mL}$ of ultrapure water at $25^{\circ} \mathrm{C} \pm 2{ }^{\circ} \mathrm{C}$ and stirred at $400 \mathrm{rpm}$. The appropriate amount sample was determined as when the obscurance level (between $2 \%$ and $8 \%$ ) was reached in the equipment [39]. For the nanoemulsion, the particle size and the polydispersity index (PDI) were determined using a Zetasizer nano ZSP (Malvern Instrument, Worcestershire, UK), where $10 \mu \mathrm{L}$ of each sample was taken and dissolved in $\sim 10 \mathrm{~mL}$ of ultrapure water. The particle size was measured via dynamic light scattering with an angle scattering of $173^{\circ}$ at $25^{\circ} \mathrm{C}$ using a quartz flow cell (ZEN0023). In this case, the instrument reported the particle size as having the mean particle diameter (z-average) and PDI ranging from 0 (monodisperse) to 1 (very broad distribution). All measurements were performed in triplicate.

\subsubsection{Viscosity}

The viscosity was measured using a viscometer (micro-visc, RheoSense Inc., San Ramon, CA, USA), applying a shear rate of $480 \mathrm{~s}^{-1}$ and $7850 \mathrm{~s}^{-1}$ for the coarse emulsion and nanoemulsion, respectively. All measurements were performed in triplicate. 


\subsubsection{Zeta Potential, Electrical Conductivity, and $\mathrm{pH}$ Measurements}

Zeta potential measurements were made using a Zetasizer nano ZSP (Malvern Instruments, Worcestershire, UK) at $25^{\circ} \mathrm{C} \pm 2{ }^{\circ} \mathrm{C}$ with an equilibration time of $120 \mathrm{~s}$ in a DTS 1070 capillary cell. For these experiments, the attenuator position and intensity were set automatically. The samples were prepared using $130 \mathrm{mg}$ of the emulsified system, which was diluted in $20 \mathrm{~mL}$ of ultrapure water and manually stirred. From this, a $50 \mu \mathrm{L}$ aliquot was taken and diluted with $1 \mathrm{~mL}$ of ultrapure water before each zeta potential measurement. Conversely, the electrical conductivity and the $\mathrm{pH}$ were determined using a conductivity meter and $\mathrm{pH}$ meter (Hanna Edge, Hanna Instruments, Woonsocket, Rhode Island, USA), respectively. All measurements were performed in triplicate.

\subsection{Analytical Methodology for Drug Quantification}

\subsubsection{Stock Solutions and Standards}

Stock solutions of CBZ with a final concentration of $1 \mathrm{mg} / \mathrm{mL}$ were prepared in triplicate, where $50.0 \mathrm{mg}$ of the drug was dissolved in $50 \mathrm{~mL}$ of methanol. Similarly, the internal standard solutions $(1 \mathrm{mg} / \mathrm{mL})$ were prepared using propyl-paraben. Briefly, $50.0 \mathrm{mg}$ of propyl-paraben was dissolved in $50 \mathrm{~mL}$ of methanol. Regarding the in vitro and in vivo release studies, calibration curves of CBZ with concentrations of 2.5, 5.0,10.0, 20.0, and $100.0 \mu \mathrm{g} / \mathrm{mL}$ were developed, which included the internal standard with a fixed concentration of $10 \mu \mathrm{g} / \mathrm{L}$. In the case of in vitro studies, methanol was used as solvent, whereas for in vivo studies, rabbit plasma was utilized as the dissolution matrix.

\subsubsection{Equipment and Chromatographic Conditions}

The quantification of CBZ was conducted via HPLC (Lachrom elite, Merck, USA) equipped with a photo diode array (PDA) detector and an automatic sampling system. The mobile phase consisted of methanol and water (40:60), and the flow rate was $1 \mathrm{~mL} / \mathrm{min}$. Separation was achieved using a $50 \mathrm{~mm} \times 4.6 \mathrm{~mm}$, Zorbax Eclipse XDB-C18 (Agilent technologies, USA) reversed-phase column with an average particle size of $1.8 \mu \mathrm{m}$, keeping the column at $25^{\circ} \mathrm{C}$. The column effluent was monitored at $265 \mathrm{~nm}$, and the chromatographic data analysis was performed with EZChrome software (Agilent technologies, USA).

\subsection{In Vitro Drug Release}

The in vitro release of CBZ from the coarse emulsions and nanoemulsions was assessed by dialysis method, using $198 \mathrm{~mL}$ of a phosphate buffer $\mathrm{pH} 7.4$ and $150 \mathrm{mM}$ as aqueous medium under sink conditions. For this, volumes of $2 \mathrm{~mL}$ of the coarse emulsions and nanoemulsions were placed in dialysis sacs (Hi-media, mol. wt. cutoff $14 \mathrm{kD}$ ) in triplicate and dialyzed at $37^{\circ} \mathrm{C}$ for $24 \mathrm{~h}$. Subsequently, the samples were taken from the external medium at intervals of $0.25,0.50,0.75,1,2,3,4,6,12$, and $24 \mathrm{~h}$.

\subsection{In Vivo Drug Release}

New Zealand breed rabbits weighing between 2.30 and $3.80 \mathrm{~kg}$ (average weight $3.26 \mathrm{~kg}$ ) were used in this study. The animals were bred in-house at the animal facility of Universidad Icesi (Cali, Colombia), in a controlled environment maintained at $25^{\circ} \mathrm{C} \pm 1{ }^{\circ} \mathrm{C}$ in separate cages with a $12 \mathrm{~h} / 12 \mathrm{~h}$ dark/light cycle and received standard food and water ad libitum. The animals were handled in accordance with Colombian guidelines for animal welfare and care (Law 84/1989 and resolution 8430/1993). The study was conducted with the approval of the Institutional Animal Ethical Committee of the Universidad Icesi. Specific care was taken to minimize animal suffering and minimize the number of animals used. Eight animals were divided randomly into two experimental groups: Group 1 (Coarse emulsion $+\mathrm{CBZ}, n=4$ ) and Group 2 (Nanoemulsion $+\mathrm{CBZ}, n=4)$. CBZ formulations were administered orally $(12.5 \mathrm{mg} / \mathrm{kg}$ body weight) with the help of a Ryles tube after about 10 to $12 \mathrm{~h}$ of 
fasting. Blood samples $(0.5 \mathrm{~mL})$ were withdrawn from the left marginal ear vein. One blood sample was taken before drug administration, and the rest of the samples were taken at the intervals of 0.25 , $0.50,1,2,3,4,6,12,18$ and $24 \mathrm{~h}$ following drug administration. The samples were centrifuged at $4000 \mathrm{rpm}$ for $10 \mathrm{~min}$ at $4{ }^{\circ} \mathrm{C}$ to separate the serum. The separated serum was stored at $-20{ }^{\circ} \mathrm{C}$ for further analysis by HPLC.

\subsection{Statistical Analysis}

The data were tabulated and analyzed using Microsoft Excel and Graph Pad Prism, respectively. The homogeneity of variance in the data was analyzed using Bartlett's test. Statistical comparisons were made using a one-way ANOVA. The Bonferroni post-hoc test was used to determine significant differences between the two independent groups. A confidence level of $95 \%$ was adopted. Data are expressed as mean \pm standard deviation.

\section{Results}

\subsection{SIO/Water Interface Physicochemical Characterization}

The CBZ characterization studies between SIO, ultrapure water, and their respective interface are shown in Figure 2, where time-dependent different behaviors were observed. In the partition study performed, it was found that CBZ tended initially CBZ to be found mainly in the SIO ( 98\%), and small amounts were present in ultrapure water $(\sim 2 \%)$, which was consistent with the tricyclic nature of CBZ's chemical structure that has a very low polarity [40]. After $8 \mathrm{~h}, \mathrm{CBZ}$ migrated into the interface and precipitated, which left very little in either phase (oil or ultrapure water). This result was very interesting because it showed that CBZ thermodynamically favored the interface rather than the oily phase, as first observed at the initial time point (Figure 2A).

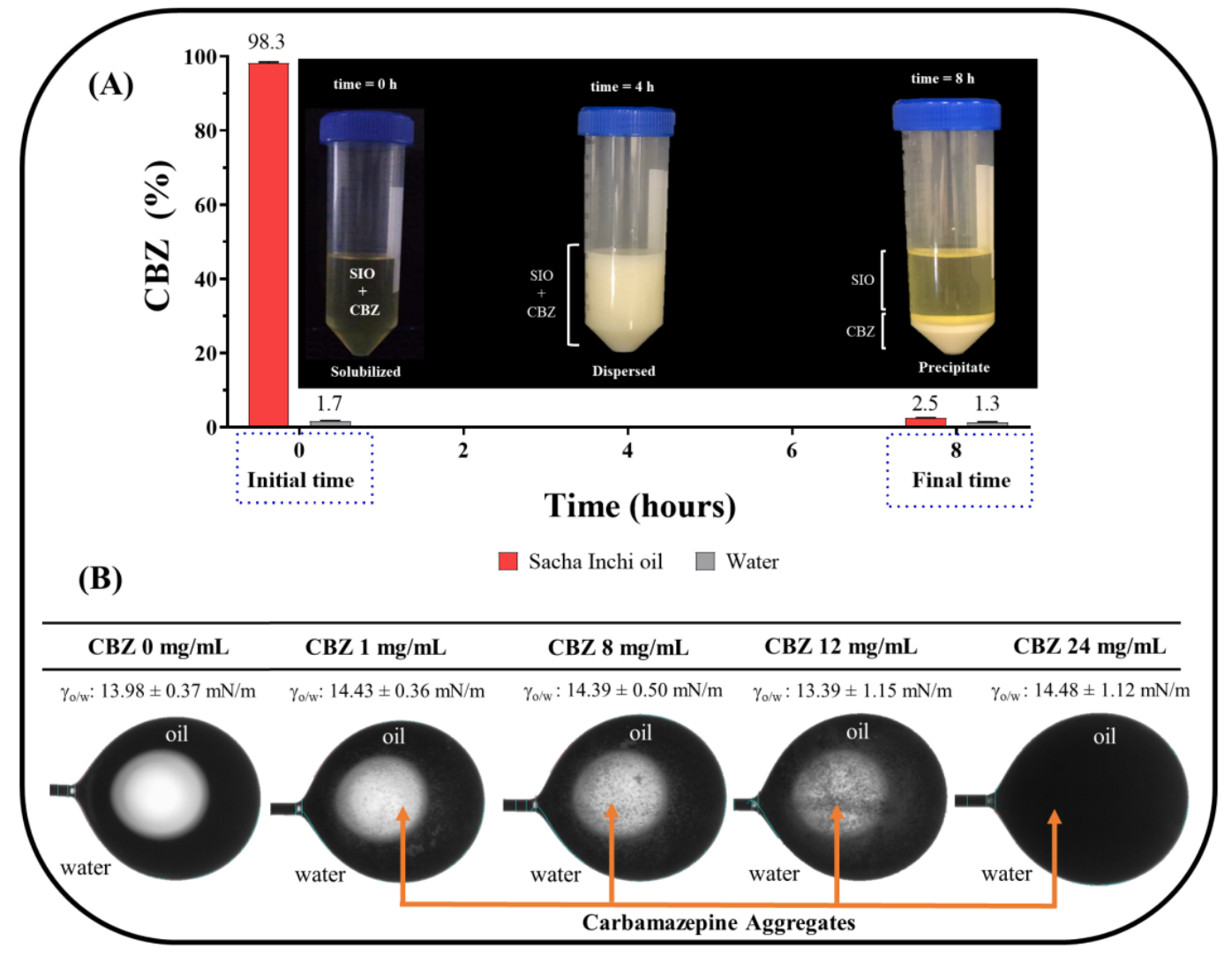

Figure 2. SIO/water interface physicochemical characterization. (A) SIO/water partition of CBZ with respect to time. (B) Effect of CBZ concentration inside oil droplets on interfacial tension. 
Interestingly, the interfacial tension evaluation exhibited a very notable effect in that this parameter fluctuated slightly, with the inside of the oil droplet changing from a translucent appearance (typical of homogeneous systems) to a very opaque appearance (typical of heterodispersed systems) (Figure 2B). This result confirmed that CBZ was solubilized in the oily phase initially (with high agitation), but over time, the CBZ began to aggregate inside the oil droplet, changing from a solution to a suspension that migrated to the interfacial zone. These results are very significant for the design stage of emulsified formulations, since these indicate that CBZ will compete with the surfactants, and the physical stability could be affected as well as the drug release.

\subsection{Elaboration of Emulsified Formulations}

The coarse emulsions presented a slightly yellowish color with a sticky and partially rough texture, while the nanoemulsions showed an intense white color and a very soft or easy-to-spread texture. The initial physicochemical characterization data for freshly prepared coarse emulsions and nanoemulsions are summarized in Table 1.

Table 1. Physicochemical characterization of freshly prepared oil-in-water coarse and nanometric emulsions.

\begin{tabular}{ccc}
\hline Physicochemical Parameter & Coarse Emulsion & Nanoemulsion \\
\hline Droplet size & $3.63 \pm 0.40 \mu \mathrm{m}$ & $320.90 \pm 1.00 \mathrm{~nm}$ \\
Viscosity & $1.93 \pm 0.02 \mathrm{cP}$ & $2.27 \pm 0.05 \mathrm{cP}$ \\
Zeta potential & $-13.69 \pm 1.20 \mathrm{mV}$ & $-11.29 \pm 0.20 \mathrm{mV}$ \\
Conductivity & $35.50 \pm 0.50 \mu \mathrm{S} / \mathrm{cm}$ & $44.30 \pm 0.70 \mu \mathrm{S} / \mathrm{cm}$ \\
$\mathrm{pH}$ & $6.10 \pm 0.05$ & $5.90 \pm 0.06$ \\
\hline
\end{tabular}

\subsection{Emulsion Stability Assay}

The results of the thermal stability for coarse emulsions and nanoemulsions are presented in Figure 3, where changes in the physicochemical parameters of creaming index (CI), droplet size, viscosity, zeta potential, conductivity, and $\mathrm{pH}$ with respect to time are described. Figure $3 \mathrm{~A}$ shows that during the first 2 days of the study, there were no marked changes in the CI in either the coarse emulsions or the nanoemulsions. However, after $48 \mathrm{~h}$, the coarse emulsions showed an increase in IC, reaching a maximum value of $12 \%$ after the second week, indicating a progressive decrease in the physical stability of the emulsion. In contrast, the nanoemulsions did not show any change in IC value, suggesting that they had greater physical stability. This result was consistent with the nanoemulsions being prepared by UHPH, where high shear energy was applied, leading to the formation of emulsified systems with very small droplet sizes and low PDI [36]. Thus, these characteristics demonstrate that nanoemulsions avoid the aggregation process between the dispersed droplets, thus providing a greater physical stability [37].

Conversely, as shown in Figure 3B, coarse emulsions and nanoemulsions tended to increase their droplet size over time. In the case of coarse emulsions, a change in droplet size from $3.63 \pm 0.40 \mu \mathrm{m}$ to $4.07 \pm 0.60 \mu \mathrm{m}$ was observed, while nanoemulsions changed from $320.9 \pm 1.0 \mathrm{~nm}$ to $338.6 \pm 8.0 \mathrm{~nm}$. Additionally, the PDI of the nanoemulsions increased from 0.22 to 0.51 . These data suggest that these systems changed from monodispersed to slightly polydispersed. These results took on more relevance when they are compared to the IC results, where smaller droplet size and PDI led to increased physical stability [25]. Contrarily, coarse emulsions with droplet sizes greater than $2 \mu \mathrm{m}$ tended to have greater differential mobility between their droplets and tended to aggregate rapidly [41]. 


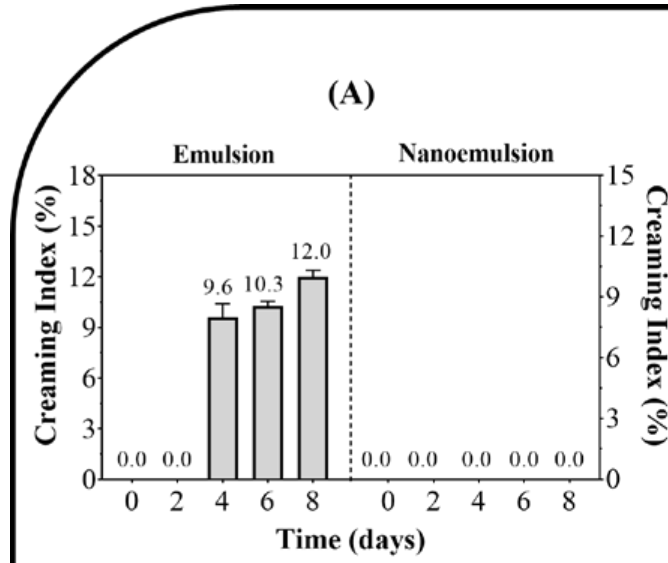

(C)

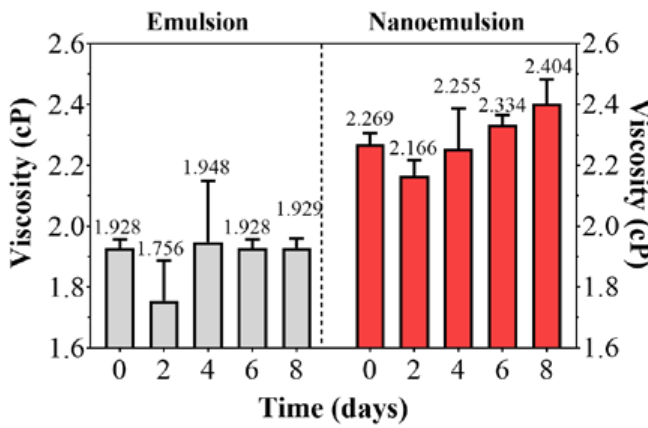

(E)

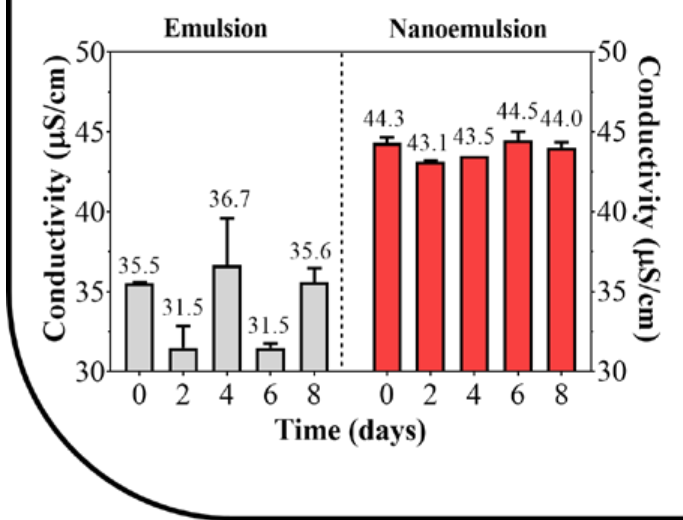

(B)

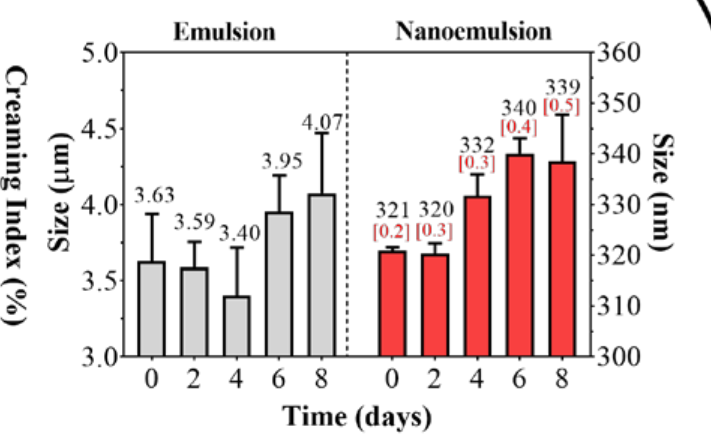

(D)

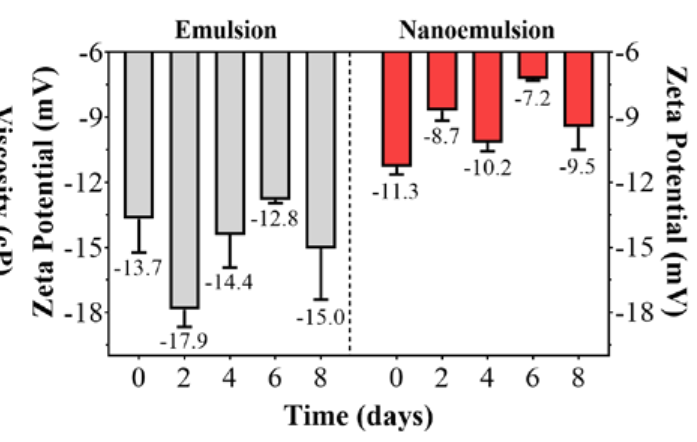

(F)

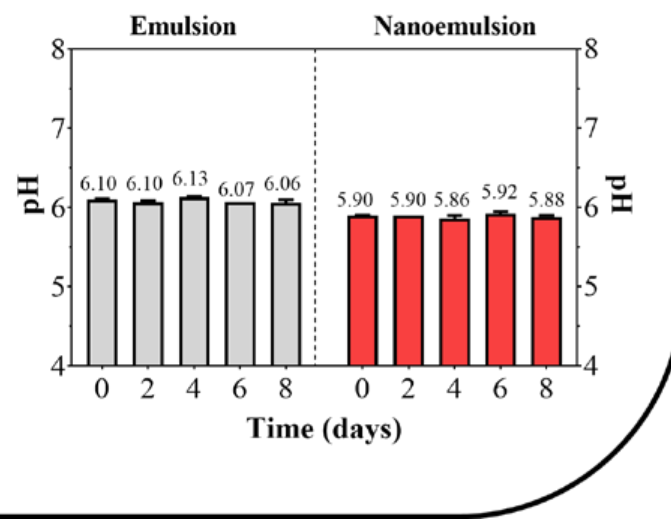

Figure 3. Results of (A) creaming index, (B) drop size, (C) viscosity, (D) zeta potential, (E) electrical conductivity, and (F) pH for coarse emulsion and nanoemulsion systems. In Figure 3B, the PDI values are presented in red brackets for the nanoemulsions only.

In relation to viscosity, Figure $3 C$ shows that both emulsified systems had very fluid external phases, where coarse emulsions had values around $1.9 \mathrm{cP}$ and nanoemulsions had values between 2.2 and $2.4 \mathrm{cP}$. This difference in the dispersed phase may be explained by the greater packaging degree and lower mobility of nanoemulsions, where the dispersed droplets were in a steady state, while the coarse emulsions were in a dynamic state [42].

Figure 3D shows that both emulsified systems had low zeta potential values that were indicative of a normal result when neutral surfactants were used (Tween ${ }^{\text {TM }} 80$ and Span ${ }^{\mathrm{TM}} 80$ ). Likewise, it was noted that zeta potential values fluctuate between $-12.82 \pm 0.50 \mathrm{mV}$ and $-17.88 \pm 1.10 \mathrm{mV}$ and $-7.23 \pm 0.02 \mathrm{mV}$ and $-11.29 \pm 0.50 \mathrm{mV}$ for coarse emulsions and nanoemulsions, respectively. This difference could also be explained by the packaging degree and the stationary condition of the dispersed 
droplets in the nanoemulsions that leaned toward lower electrophoretic mobility, and therefore a lower zeta potential value [43].

In relation to the electrical conductivity in the external phase, Figure $3 \mathrm{E}$ shows the different behaviors of the emulsified system. For coarse emulsions, low and fluctuating values (31.5 and $35.5 \mu \mathrm{S} / \mathrm{cm}$ ) were obtained, while for nanoemulsions, slightly higher and constant values were obtained (43.1 and $44.5 \mu \mathrm{S} / \mathrm{cm}$ ). This behavior also supported the previous results, where nanoemulsified systems tended to form more organized monodispersed structures where the ionic species (preservatives) could move easily in the external phase of the emulsion. Finally, Figure 3F shows that coarse emulsions and nanoemulsions had $\mathrm{pH}$ values between 5.9 and 6.1. This result was consistent with acidic paraben preservatives [44]. Additionally, the $\mathrm{pH}$ values were almost constant, which suggested chemical integrity of the formulation ingredients.

\subsection{Analytical Methodology for Drug Quantification}

In accordance with the ICH standards [45], the results of the non-exhaustive validation for the analytical methods of CBZ quantification are summarized in Table 2.

Table 2. Validation of non-exhaustive analytical method for CBZ quantitation.

\begin{tabular}{ccc}
\hline Parameter & In Vitro Correlation Curve & In Vivo Correlation Curve \\
\hline Linear equation $X(\mu \mathrm{g} / \mathrm{mL})$ & $\mathrm{Y}=0.026 \mathrm{X}+0.0875$ & $\mathrm{Y}=0.042 \mathrm{X}+0.0219$ \\
Correlation coefficient & 0.9973 & 0.9997 \\
Detection limit $(\mu \mathrm{g} / \mathrm{mL})$ & 0.015 & 0.020 \\
Quantitation limit $(\mu \mathrm{g} / \mathrm{mL})$ & 0.15 & 0.20 \\
Intra-day method RSD $(\%)$ & 0.40 & 1.40 \\
Inter-day method RSD $(\%)$ & 1.59 & 2.40 \\
\hline
\end{tabular}

RSD: residual standard deviation.

The results in Table 2 show that the correlation coefficients values for the calibration curves in in vitro and in vivo studies were 0.9973 and 0.9997 , respectively. The calibration curves complied with the linearity validation parameter and the data obtained fitted very well to the heuristic model, $y=m x+b$, where $y$ is the analytical signal, $m$ is the line slope, $x$ is the CBZ concentration in units of $\mu \mathrm{g} / \mathrm{mL}$ and $b$ is the intercept. Likewise, it was found that CBZ detection and quantification limits presented a 10-fold concentration difference factor, and the analytical method reproducibility, expressed as the RSD, was always less than $5 \%$.

\subsection{In Vitro Drug Release}

Figure $4 \mathrm{~A}$ shows the in vitro release profiles of $\mathrm{CBZ}$ from coarse emulsions and nanoemulsions. Both emulsions had a rapid release (burst release) in the first hours, followed by a deceleration [46]. It is important to note that CBZ release was extremely low $(<2 \%)$ in the coarse emulsions as well as nanoemulsions at very early time points. The CBZ release was lower than anticipated based on the results of previous publications examining emulsified CBZ systems [47-51]. However, the previous studies examined CBZ release under different conditions: (i) CBZ in lower amounts, (ii) different types of oil phase, (iii) higher concentrations of surfactants, and (iv) use of dialysis membranes with large cutoff sizes. In contrast, in this study, a high amount of CBZ was used with a minimum quantity of surfactants $(2 \%)$ to guarantee that the drug was vehiculized in the emulsified systems and not in other types of colloidal structures like micelles. In addition, dialysis membranes with smaller cutoff size were employed (14 kDa) to more closely mimic actual biological conditions [52,53]. To further expound upon the low amount of CBZ released from both emulsification systems, it is necessary to consider the drug characterizations made in previous studies with $\mathrm{SIO}$, ultrapure water, and the respective interface. First, the $\mathrm{SIO} /$ water partition and the interfacial tension evaluations showed that CBZ has a very poor solubility in both emulsion phases (oily and aqueous), and spontaneously tends to both precipitate and migrate to the interface. Thus, the CBZ diffusion into the aqueous phase of the emulsion (external 
phase) is considerably limited. It is limited to an even greater degree in the second aqueous external phase of the two-compartment dialysis system (Figure 4B). Second, taking into account the larger pore size of the dialysis membrane used in the previous studies, and the nature of $\mathrm{CBZ}$ forming aggregates and heterogeneous dispersions in aqueous medium, it is possible to understand how our results, which employed dialysis membranes with smaller pore sizes, led to a lower CBZ release from both emulsified systems. However, it is important to highlight that these results of in vitro carbamazepine release, instead of providing clarity about its release mechanism from such emulsified systems, generated more doubts, which should be considered in subsequent investigations. Thus, the biopharmaceutical classification system of the drug, the load of drug in the emulsions, the membrane type, the membrane cut-off, and the $\mathrm{pH}$ of the medium, especially at levels that simulate the gastrointestinal tract $(1.2 ; 4.5$ and 6.8), should be considered and studied in more depth to clarify these in vitro release mechanisms.

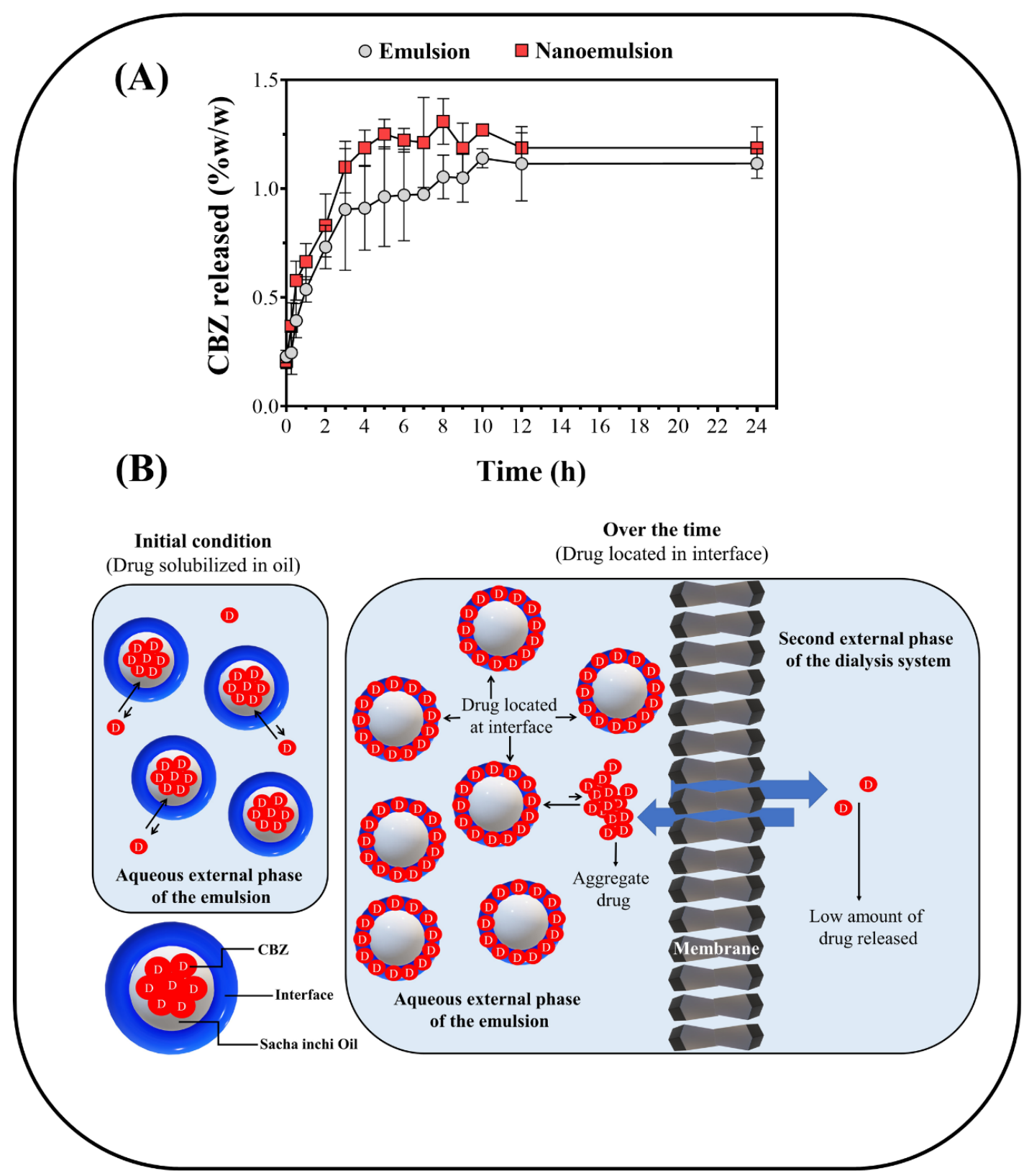

Figure 4. (A) In vitro CBZ release for emulsion and nanoemulsion formulations. (B) Scheme of CBZ migration from the oily phase to the interfacial zone, affecting the drug's permeability. 


\subsection{In Vivo Drug Release}

The results of CBZ in vivo release are presented in Figure 5. A 10-fold increase in drug concentration was found in vivo compared to the in vitro release studies. The maximum plasma concentration $\left(C_{\max }\right)$ of CBZ was $\sim 19 \mu \mathrm{g} / \mathrm{mL}$ in the coarse emulsions and nanoemulsions (Figure 5), which corresponded to $20 \% w / w$ of CBZ absorbed. Although these results were similar to the plasma CBZ concentrationd previously found in other animal models and in other dosage forms [54], it is necessary to highlight that these results differed greatly from the usual reported values for this drug $(>60 \% w / w)$ [55]. It was also observed that the differences between the droplet sizes of the emulsified formulations did not significantly affect CBZ plasma concentration; however, it should be noted that the time in which the maximum plasma concentrations $\left(t_{\max }\right)$ was reached depended considerably on the type of emulsified system. In the case of coarse emulsions, it was found that the $t_{\max }$ was $12 \mathrm{~h}$. The $t_{\max }$ for nanoemulsions was found to be $45 \mathrm{~min}$, and this corresponded to a considerable change in the drug absorption rate, which is a remarkable and promising result. These results suggest that nanoemulsified formulations may have different absorption mechanisms, where smaller droplets can more easily permeate the gastrointestinal wall and endothelial membranes, thereby rapidly achieving the desired concentration in the blood plasma, and this might have the potential to increase bioavailability.

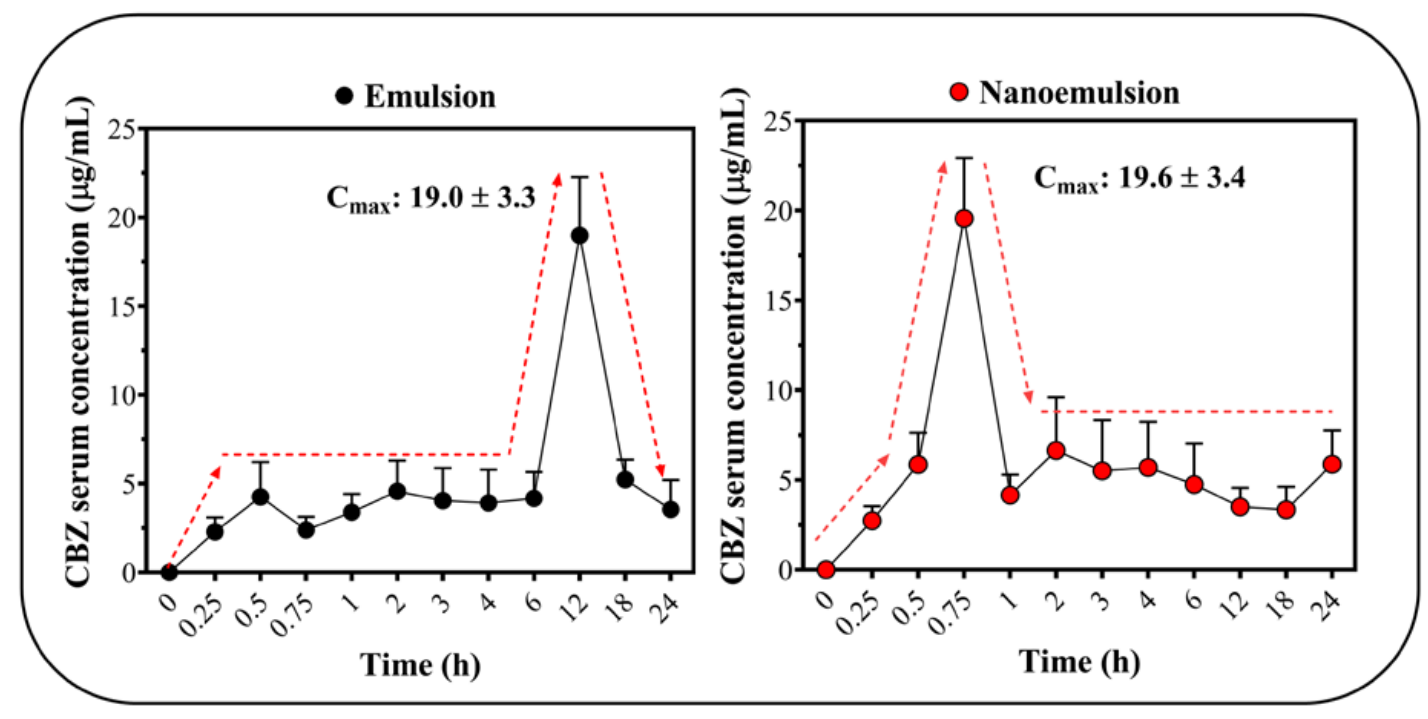

Figure 5. CBZ blood concentration released from coarse emulsion and nanoemulsion formulations.

These results confirm that nanoformulations of conventional drugs are very promising alternatives to traditional drug delivery methods and continue to further the research into improving the physicochemical and biopharmaceutical features of conventional pharmaceuticals.

\section{Conclusions}

CBZ showed a low affinity for the oily and aqueous phases and tended to spontaneously migrate toward the interfacial zone over time. UHPH resulted in a remarkable improvement in the sensorial characteristics of the nanoemulsions, as well as the physical stability of the coarse emulsions, leading to the creation of emulsified formulations with an intense white appearance and a soft texture due to their small and monodispersed droplets $(\sim 320 \mathrm{~nm}$ and PDI $<0.3)$. The release of CBZ in vitro was low for both emulsified formulations $(<2 \% w / w)$, which was attributed to the remarkable predilection of the drug for the $\mathrm{SIO} /$ water interface, affecting its diffusion to the emulsion external phase as well as its diffusion to the second aqueous phase in a two-compartment dialysis system. However, these results are not conclusive, and it is therefore necessary to carry out more studies focused on clarifying this behavior. Thus, the effect of the drug load on the emulsion, the type of membrane, the pore size of the membrane, and the $\mathrm{pH}$ of the gastrointestinal medium with respect to the drug release 
should be studied. In contrast, the in vivo CBZ release study had a maximum plasma concentration 10 -fold higher than the in vitro study, which corresponded to $\sim 20 \% w / w$. Although the concentration values typically reported for orally administered CBZ $(>60 \% w / w)$ are greater than those obtained in this study, the maximum absorption times were considerably decreased in this study. The time to absorption of CBZ is dependent on the formulation. CBZ nanoemulsions were able to dramatically decrease the time to maximum absorption, from $12 \mathrm{~h}$ with the coarse emulsions to just $45 \mathrm{~min}$, indicating a great improvement in bioavailability. These data show that nanoformulations provide a rich and fertile research landscape for the development of innovative dosage forms of conventional pharmaceutical drugs.

Author Contributions: Methodology and investigation, J.D.E.; M.J.A.; N.M.; A.B.-O.; C.J.Y. writing—original draft preparation, C.J.Y., J.D.E.; supervision, writing-review and editing, C.H.S. All authors have read and agreed to the published version of the manuscript.

Funding: This work was supported by the Icesi University [Internal grant number CA040201].

Acknowledgments: The authors thank to Nutresacha S.A. company and Tecnoquimicas S.A Pharmaceutical Company from Colombia to provide the Sacha inchi Oil and Carbamazepine used in this study.

Conflicts of Interest: The authors declare no conflict of interest.

\section{References}

1. Shekhawat, P.B.; Pokharkar, V.B. Understanding peroral absorption: Regulatory aspects and contemporary approaches to tackling solubility and permeability hurdles. Acta Pharm. Sin. B 2017, 7, 260-280. [CrossRef]

2. Siya, M.; Kunde, D.S.; Bhilegaonkar, S.; Godbole, A.M.; Gajre, M.P. Biopharmaceutical classification system: A brief account. Int. J. Res. Methodol. 2015, 1, 20-46.

3. Yasir, M.; Asif, M.; Kumar, A.; Aggarval, A. Biopharmaceutical classification system: An account. Int. J. PharmTech Res. 2010, 2, 1681-1690.

4. $\mathrm{Ku}$, M.S. Use of the biopharmaceutical classification system in early drug development. AAPS J. 2008, 10, 208-212. [CrossRef]

5. Kansara, H.; Panola, R.; Mishra, A. Techniques used to enhance bioavailability of bcs class II drugs: A review. Int. J. Drug Dev. Res. 2015, 7, 82-93.

6. Buckley, S.T.; Frank, K.J.; Fricker, G.; Brandl, M. Biopharmaceutical classification of poorly soluble drugs with respect to "enabling formulations". Eur. J. Pharm. Sci. 2013, 50, 8-16. [CrossRef] [PubMed]

7. Elmeshad, A.N.; Mortazavi, S.M.; Mozafari, M.R. Formulation and characterization of nanoliposomal 5-fluorouracil for cancer nanotherapy. J. Liposome Res. 2014, 24, 1-9. [CrossRef] [PubMed]

8. Noble, C.O.; Guo, Z.; Hayes, M.E.; Marks, J.D.; Park, J.W.; Benz, C.C.; Kirpotin, D.B.; Drummond, D.C. Characterization of highly stable liposomal and immunoliposomal formulations of vincristine and vinblastine. Cancer Chemother. Pharmacol. 2009, 64, 741-751. [CrossRef] [PubMed]

9. Mozafari, M.R. Nanoliposomes: Preparation and analysis. Methods Mol. Biol. 2010, 605, 29-50. [CrossRef]

10. Du, B.; Li, Y.; Li, X.; A, Y.; Chen, C.; Zhang, Z. Preparation, characterization and in vivo evaluation of 2-methoxyestradiol-loaded liposomes. Int. J. Pharm. 2010, 384, 140-147. [CrossRef]

11. Panahi, Y.; Farshbaf, M.; Mohammadhosseini, M.; Mirahadi, M.; Khalilov, R.; Saghfi, S.; Akbarzadeh, A. Recent advances on liposomal nanoparticles: Synthesis, characterization and biomedical applications. Artif. Cells Nanomedicine Biotechnol. 2017, 45, 788-799. [CrossRef] [PubMed]

12. Zoghi, A.; Khosravi-Darani, K.; Omri, A. Process variables and design of experiments in liposome and nanoliposome research. Mini Rev. Med. Chem. 2018, 18, 324-344. [CrossRef] [PubMed]

13. Fang, R.; Yang, S.; Wang, Y.; Qian, H. Nanoscale drug delivery systems: A current review on the promising paclitaxel formulations for future cancer therapy. Nano Br. Rep. Rev. 2015, 10, 150310190305009. [CrossRef]

14. Soppimath, K.S.; Aminabhavi, T.M.; Kulkarni, A.R.; Rudzinski, W.E. Biodegradable polymeric nanoparticles as drug delivery devices. J. Control. Release 2001, 70, 1-20. [CrossRef]

15. Vauthier, C.; Bouchemal, K. Methods for the preparation and manufacture of polymeric nanoparticles. Pharm. Res. 2009, 26, 1025-1058. [CrossRef]

16. Patel, T.; Zhou, J.; Piepmeier, J.M.; Saltzman, W.M. Polymeric nanoparticles for drug delivery to the central nervous system. Adv. Drug Deliv. Rev. 2012, 64, 701-705. [CrossRef] 
17. Ensign, L.M.; Cone, R.; Hanes, J. Oral drug delivery with polymeric nanoparticles: The gastrointestinal mucus barriers. Adv. Drug Deliv. Rev. 2012, 64, 557-570. [CrossRef]

18. Yadav, N.; Khatak, S.; Sara, U.V.S. Solid lipid nanoparticles-A review. Int. J. Appl. Pharm. 2013, 5, 8-18. [CrossRef]

19. Kalhapure, R.S.; Suleman, N.; Mocktar, C.; Seedat, N.; Govender, T. Nanoengineered drug delivery systems for enhancing antibiotic therapy. J. Pharm. Sci. 2015, 104, 872-905. [CrossRef]

20. Shah, P.; Bhalodia, D.; Shelat, P. Nanoemulsion: A pharmaceutical review. Syst. Rev. Pharm. 2010, 1, $24-32$. [CrossRef]

21. Rai, V.K.; Mishra, N.; Yadav, K.S.; Yadav, N.P. Nanoemulsion as pharmaceutical carrier for dermal and transdermal drug delivery: Formulation development, stability issues, basic considerations and applications. J. Control. Release 2018, 270, 203-225. [CrossRef] [PubMed]

22. Sutradhar, K.B.; Amin, L. Nanoemulsions: Increasing possibilities in drug delivery. Eur. J. Nanomedicine 2013, 5, 97-110. [CrossRef]

23. Pagar, K.R.; Darekar, A.B. Nanoemulsion: A new concept of delivery system. Asian J. Res. Pharm. Sci. 2019, 9, 39. [CrossRef]

24. Nanoemulsions: A review on various pharmaceutical application. Glob. J. Pharmacol. 2012, 6, 222-225.

25. Jaiswal, M.; Dudhe, R.; Sharma, P.K. Nanoemulsion: An advanced mode of drug delivery system. 3 Biotech 2015, 5, 123-127. [CrossRef] [PubMed]

26. Nakaya, K.; Kohata, T.; Doisaki, N.; Ushio, H.; Ohshima, T. Effect of oil droplet sizes of oil-in-water emulsion on the taste impressions of added tastants. Fish. Sci. 2006, 72, 877-883. [CrossRef]

27. Donsì, F.; Sessa, M.; Mediouni, H.; Mgaidi, A.; Ferrari, G. Encapsulation of bioactive compounds in nanoemulsion- based delivery systems. Procedia Food Sci. 2011, 1, 1666-1671. [CrossRef]

28. Naseri, N.; Valizadeh, H.; Zakeri-Milani, P. Solid lipid nanoparticles and nanostructured lipid carriers: Structure preparation and application. Adv. Pharm. Bull. 2015, 5, 305-313. [CrossRef]

29. Emulsion Stability and Testing-Particle Sciences. Available online: https://mafiadoc.com/emulsion-stabilityand-testing-particle-sciences_5b93a41a097c4760198b4605.html (accessed on 25 March 2020).

30. McClements, D.J.; Li, Y. Review of in vitro digestion models for rapid screening of emulsion-based systems. Food Funct. 2010, 1, 32-59. [CrossRef]

31. Ashara, K.C.; Paun, J.S.; Soniwala, M.M.; Chavada, J.R.; Mori, N.M. Micro-emulsion based emulgel: A novel topical drug delivery system. Asian Pac. J. Trop. Dis. 2014, 4, S27-S32. [CrossRef]

32. Dumay, E.; Chevalier-Lucia, D.; Picart-Palmade, L.; Benzaria, A.; Gràcia-Julià, A.; Blayo, C. Technological aspects and potential applications of (ultra) high-pressure homogenisation. Trends Food Sci. Technol. 2013, 31, 13-26. [CrossRef]

33. Briviba, K.; Gräf, V.; Walz, E.; Guamis, B.; Butz, P. Ultra high pressure homogenization of almond milk: Physico-chemical and physiological effects. Food Chem. 2016, 192, 82-89. [CrossRef] [PubMed]

34. Pereda, J.; Ferragut, V.; Quevedo, J.M.; Guamis, B.; Trujillo, A.J. Effects of ultra-high pressure homogenization on microbial and physicochemical shelf life of milk. J. Dairy Sci. 2007, 90, 1081-1093. [CrossRef]

35. Poliseli-Scopel, F.H.; Hernández-Herrero, M.; Guamis, B.; Ferragut, V. Comparison of ultra high pressure homogenization and conventional thermal treatments on the microbiological, physical and chemical quality of soymilk. LWT Food Sci. Technol. 2012, 43, 42-48. [CrossRef]

36. Zamora, A.; Ferragut, V.; Jaramillo, P.D.; Guamis, B.; Trujillo, A.J. Effects of ultra-high pressure homogenization on the cheese-making properties of milk. J. Dairy Sci. 2007, 90, 13-23. [CrossRef]

37. Rave, M.C.; Echeverri, J.D.; Salamanca, C.H. Improvement of the physical stability of oil-in-water nanoemulsions elaborated with Sacha inchi oil employing ultra-high-pressure homogenization. J. Food Eng. 2020, 273, 109801. [CrossRef]

38. Penagos-Calvete, D.; Duque, V.; Marimon, C.; Parra, D.M.; Restrepo-Arango, S.K.; Scherf-Clavel, O.; Holzgrabe, U.; Montoya, G.; Salamanca, C.H. Glycerolipid composition and advanced physicochemical considerations of sacha inchi oil toward cosmetic products formulation. Cosmetics 2019, 6. [CrossRef]

39. Coupland, J.N.; McClements, D.J. Droplet size determination in food emulsions: Comparison of ultrasonic and light scattering methods. J. Food Eng. 2001, 50, 117-120. [CrossRef]

40. Kobayashi, Y.; Ito, S.; Itai, S.; Yamamoto, K. Physicochemical properties and bioavailability of carbamazepine polymorphs and dihydrate. Int. J. Pharm. 2000, 193, 137-146. [CrossRef] 
41. Ruckenstein, E. Thermodynamic insights on macroemulsion stability. Adv. Colloid Interface Sci. 1999, 79, 59-76. [CrossRef]

42. Pal, R. Effect of droplet size on the rheology of emulsions. AIChE J. 1996, 42, 3181-3190. [CrossRef]

43. Wiacek, A.; Chibowski, E. Zeta potential, effective diameter and multimodal size distribution in oil/water emulsion. Colloids Surf. Physicochem. Eng. Asp. 1999, 159, 253-261. [CrossRef]

44. Blaug, S.M.; Grant, D.E. Kinetics of degradation of the parabens. J. Soc. Cosmet. Chem. Jpn. 1974, 25, 495-506.

45. Shabir, G.A. Validation of high-performance liquid chromatography methods for pharmaceutical analysis: Understanding the differences and similarities between validation requirements of the US Food and Drug Administration, the US Pharmacopeia and the International Conf. J. Chromatogr. A 2003, 987, 57-66. [CrossRef]

46. Huang, X.; Brazel, C.S. On the importance and mechanisms of burst release in matrix-controlled drug delivery systems. J. Control. Release 2001, 73, 121-136. [CrossRef]

47. Tan, S.; Stanslas, J.; Basri, M.; A, A.K.R.; Kirby, B.; Sani, D.; Basri, H. Nanoemulsion-based parenteral drug delivery system of carbamazepine: Preparation, characterization, stability evaluation and blood-brain pharmacokinetics. Curr. Drug Deliv. 2015, 12, 795-804. [CrossRef]

48. Meyer, M.C.; Straughn, A.B.; Jarvi, E.J.; Wood, G.C.; Pelsor, F.R.; Shah, V.P. The bioinequivalence of carbamazepine tablets with a history of clinical failures. Pharm. Res. Off. J. Am. Assoc. Pharm. Sci. 1992, 9, 1612-1616. [CrossRef]

49. Wang, Z.; Chen, B.; Quan, G.; Li, F.; Wu, Q.; Dian, L.; Dong, Y.; Li, G.; Wu, C. Increasing the oral bioavailability of poorly water-soluble carbamazepine using immediate-release pellets supported on SBA-15 mesoporous silica. Int. J. Nanomedicine 2012, 7, 5807-5818. [CrossRef]

50. Olling, M.; Mensinga, T.T.; Barends, D.M.; Groen, C.; Lake, O.A.; Meulenbelt, J. Bioavailability of carbamazepine from four different products and the occurrence of side effects. Biopharm. Drug Dispos. 1999, 20, 19-28. [CrossRef]

51. HARTLEY, R.; ALEKSANDROWICZ, J.; BOWMER, C.J.; CAWOOD, A.; FORSYTHE, W.I. Dissolution and relative bioavailability of two carbamazepine preparations for children with epilepsy. J. Pharm. Pharmacol. 1991, 43, 117-119. [CrossRef]

52. Howorka, S.; Siwy, Z. Nanopores: Generation, engineering, and single-molecule applications. In Handbook of Single-Molecule Biophys; Springer: New York, NY, USA, 2009; pp. 293-339. [CrossRef]

53. Omidi, Y.; Gumbleton, M. Biological membranes and barriers. In Biomaterials for Delivery and Targeting of Proteins and Nucleic Acids; CRC Press: New York, NY, USA, 2004; pp. 231-274. ISBN 9780203492321.

54. Chaudhary, A.; Nagaich, U.; Gulati, N.; Sharma, V.; Khosa, R.; Partapur, M. Enhancement of solubilization and bioavailability of poorly soluble drugs by physical and chemical modifications: A recent review. J. Adv. Pharm. Educ. Res. 2012, 2, 32-67.

55. Cotter, L.M.; Smith, G.; Hooper, W.D. The bioavailability of carbamazepine. Proc. Aust. Assoc. Neurol. 1975, 12, 123-128. [CrossRef]

(C) 2020 by the authors. Licensee MDPI, Basel, Switzerland. This article is an open access article distributed under the terms and conditions of the Creative Commons Attribution (CC BY) license (http://creativecommons.org/licenses/by/4.0/). 